\title{
Nicola Pozza*
}

\section{Becoming a Crorepati: From Glocal TV Game to Grobal Fiction}

https://doi.org/10.1515/asia-2019-0053

\begin{abstract}
Numerous studies have dealt with the process of globalization and its various cultural products. Three such cultural products illustrate this process: Vikas Swarup's novel $Q$ and A (2005), the TV quiz show Kaun banega crorepati? (Who Wants to Be a Millionaire?), and Danny Boyle's film Slumdog Millionaire (2008). The novel, the TV show and the film have so far been studied separately. Juxtaposing and comparing $Q$ and $A$, Kaun banega crorepati, and Slumdog Millionaire provides an effective means to shed light on the dialogic and interactive nature of the process of globalization. It is argued through this case study that an analysis of their place of production, language and content, helps clarify the derivative concepts of "glocalization" and "grobalization" with regard to the way(s) contemporary cultural products respond to globalization.
\end{abstract}

Keywords: Globalization, TV Entertainment, KBC, Slumdog Millionaire, Indian fiction

\section{Comparing global products in the light of glocalization}

\subsection{Semantic contextualization}

In the last decades of the twentieth century, the response to the growing influence of economic globalization ${ }^{1}$ has often been that of a "return to the

1 Giddens (1990: 64) defines "globalization" as "the intensification of worldwide social relations which link distant localities in such a way that local happenings are shaped by events occurring many miles away and vice versa." Robertson (1992: 142), however, who offers a critical evaluation of Giddens's approach to this concept in chapter 9 of his Globalization, sees Giddens's definition as "simply an enlargement of modernity, from society to the world". Robertson (1992: 8) insists on the necessity to recognise that "globalization is not equated with or seen as a direct consequence of an amorphously conceived modernity". Rather, it consists in

*Corresponding author: Nicola Pozza, University of Lausanne, Lausanne, Switzerland.

E-mail: nicola.pozza@unil.ch 
local."2 The dynamic relation between the two polar extremes, global/local, ${ }^{3}$ gave birth to the term "glocalization", which was first introduced in sociology by Roland Robertson in 1994. Conceived as a way to counteract the tendency to see globalization as "a process which overrides locality", ${ }^{4}$ it was inspired by the Japanese term dochakuka, "roughly meaning 'global localization'”. 5 George Ritzer offers a concise and clear definition of "glocalization", saying that it is, "the interpenetration of the global and the local resulting in unique outcomes in different geographic areas". ${ }^{6}$ The advantage of such an understanding of cultural processes that differs from the global/local dichotomy is that, while "the antithesis of global and local collapses too readily into familiar binaries (e. $g$. abstract/concrete, mind/body), a robust sense of glocality can grasp the production of place by a constant, often conflictual, working and reworking of practices, discourses, and more or less durable institutions". ${ }^{7}$

Pursuing and extending the work of Robertson, Ritzer feels it necessary, however, to develop a second concept, grobalization, in order to complement the concept of glocalization, because "these two processes coexist under the broad heading of globalization". ${ }^{8}$ In his terms, the concept of "grobalization",

focuses on the imperialistic ambitions of nations, corporations, organizations, and the like and their desire, indeed need, to impose themselves on various geographic areas. Their main interest is in seeing their power, influence, and in some cases profits grow (hence the term grobalization) throughout the world. ${ }^{9}$

\footnotetext{
"the increasing acceleration in both concrete global interdependence and consciousness of the global whole in the twentieth century" (1992: 8). Another largely accepted definition of "globalization" is provided by Lechner (2005: 330), who describes it as "the worldwide diffusion of practices, expansion of relations across continents, organisation of social life on a global scale, and growth of a shared global consciousness". Of course, globalization is not a new phenomenon at all. According to Hall, what is new in it (i. e. since the 1980s) is the fact that it is no longer linked to national economies and national cultural identities (predominantly English), but to a "new form of global mass culture [...] dominated by the image which crosses and recrosses linguistic frontiers much more rapidly and more easily" (1991: 27; emphasis is mine).

2 Hall 1991: 33.

3 On the global/local distinction, see Wilson/Dissanayake 1996.

4 Robertson 1994: 34.

5 Robertson 1992: 173.

6 Ritzer 2004: 73.

7 Livingston 2001: 149.

8 Ritzer 2004: 74.

9 Ritzer 2004: 73. Ritzer feels apologetic to add such a neologism; however, he believes that "the existence and popularity of the concept of glocalization requires the creation of the parallel notion of grobalization in order to emphasize that which the former concept ignores, downplays, or rejects” (Ritzer 2003: 194, n.7).
} 
According to this perspective, which will help us analyse the narratives selected for the research presented here, the concept of glocalization emphasises the process of localization and particularization of a product from its global production, while the idea of grobalization stresses the spread, the growth, of a specific product towards a wider, global public, by making use of soft power resources. ${ }^{10}$

\subsection{Comparing three global narratives: $K B C, Q$ and $A$, and Slumdog Millionaire}

The concept of "globalization" and other related ones such as "transnational" have now been applied in numerous studies on the world of Bollywood and its successful spread in the West. ${ }^{11}$ This is also the case for the film Slumdog Millionaire (2008, hereafter SDM), which has been the focus of several essays. ${ }^{12}$ Far fewer studies have dealt with the quiz show Kaun banega crorepati? (hereafter $\mathrm{KBC}){ }^{13}$ and even fewer with Vikas Swarup's novel $Q$ and $A$ (2005, hereafter Q\&A). ${ }^{14}$

If each of these cultural products (SDM, KBC, and Q\&A) represents a perfect illustration of the process of globalization, no study yet has dealt with all of them together. At best, a comparative analysis of the novel and its film adaptation has been made by Bulger (2009) and by Vanfasse (2012), while Desai (2011) has worked on both the film and the TV quiz show. If each individual study certainly brings insightful comments and arguments on the local/global nature of its topic of analysis, it might be all the more heuristically useful to examine these three cultural

10 On "soft power", see Nye 2004.

11 See, for instance, Bhattacharya 2013, Bhattacharya Mehta/Pandharipande 2011, Dudrah 2012, Gehlawat 2015, Joshi 2010, Kaur/Sinha 2005, Roy/Huat 2012, Schaefer/Karan 2013, Thussu 2008. Bollywood movies, or popular Hindi films, have, however, been successful as early as the 1950s in the former European Eastern Bloc, South and Central America, South East Asia, the Middle East, and continental Africa (Joshi 2010: 246, Roy/Huat 2012: xii, Thussu 2008: 100), but their acknowledgment in the West - mostly because of the Indian diaspora - is only a recent phenomenon.

12 Amongst others, Banaji 2010, Bardhan 2011, Bhattacharya 2009, Gehlawat 2013, Ghosh 2015, Lamsal 2010, Mendes 2010, Mudambi 2013, Raj/Sreekumar 2011, Stephens Duncan 2011, Thobani 2009, Tyree 2009. Hall (1991: 27) is right when he says that actual globalization "is dominated by television and by film, and by the image, imagery, and styles of mass advertising"; TV quiz shows like KBC, or a movie like SDM, are good proof of this. All the more, the success of Q\&A, despite its written form, certainly owes much to its very cinematic and narrative nature.

13 Ranjan/Sehdev/Bhatnagar 2013, Roy 2011, Thomas 2006, Visvanathan 2000.

14 Banerjee 2013, Korte 2010/2011, Snell 2016. 
products in comparison to each other. For instance, Thomas (2006: 43) has described the success of TV programmes as "the skilful hybridising of a 'global' programme format with 'local' cultural nuances." Can we extrapolate this formula to be valid for all three cultural products mentioned here, or does their respective success depend on different criteria? Can the "glocal/grobal" conceptual pairing proposed by Ritzer (2003) bring some new insight into the apprehension of the dynamic of these contemporary global narratives?

By analysing and comparing in a contrastive way KBC, Q\&A and SDM according to their respective place of production, language, and content, it is argued here that their comparison provides an effective means to shed light on the dialogic and interactive nature of the process of globalization. Moreover, it helps clarify the derivative concepts of "glocalization" and "grobalization" with regard to the way(s) contemporary narratives respond to globalization. The comparative analysis of the three selected cultural products that is proposed in this case study follows a three-part structure. It is based: (1) on their respective geographical background and conditions of production, their target audience, and their reception; (2) on the language(s) used in them; and (3) on their main "characters", places of action, and contents (questions, events, etc.). This will lead us to the concluding remarks on the different forms of "glocalization" and "grobalization" at work in the three analysed narratives, and on the still dominant perception of western-based references being part of a universal knowledge versus Indian-based references being attached to the ideas of "locality" and "authenticity".

\section{Comparative analysis of $\mathrm{KBC}, Q$ and $A$, and Slumdog Millionaire}

\subsection{Background of production, target audience, and reception of the narratives}

\subsubsection{KBC}

Originally created in the UK in September $1998,{ }^{15}$ the TV game show Who Wants to Be a Millionaire? has been produced in Hindi since 2000 under the name Kaun

15 In the UK, the show closed on February 4, 2014, before returning for two new short series in 2018 and 2019. 
Banega Crorepati (KBC), and hosted by the world-famous Bollywood star Amitabh Bachchan (except for the third season, in 2007, when it was led by another Bollywood star, Shahrukh Khan). Seven other Indian versions have been produced to date, as well as more than a hundred different national or regional versions throughout the world. KBC "was first suggested by the Hong Kongbased head of Asia-Pacific programming for StarTV [...] who sent a video of the original programme to Bombay". ${ }^{16}$ The complete process of the creation of KBC is a perfect illustration of today's globalization in the media. ${ }^{17}$ To develop the Indian version, which was meant to radically transform the Indian landscape of television programming, ${ }^{18}$ three staff members of Celador Entertainment, the British television production company (that produced SDM too), "were seconded to India to train the local production team, and later a team of four from India were sent to the US for further familiarisation with the concept". ${ }^{19}$ The choice to employ Amitabh Bachchan as the host of KBC was made by a local StarTV (Satellite Television Asian Region) executive. The "local questions were designed by Siddhartha Basu," producer for KBC, "along with the help of a team of researchers". ${ }^{20}$ During the first three seasons (2000-2001, 2005-2006, 2007), the show was broadcast on the channel Star Plus, a part of StarTV. This was owned by twenty-first Century Fox, whose majority stakeholder was at that time by the media mogul Rupert Murdoch. ${ }^{21}$ In 2010, the show was aired on Sony Pictures Television, and the eleventh season was broadcast in 2019.

Although KBC is the result of a global process and is hosted by one of the most widely known Indian actors, it was, from its very beginning, meant to be locally rooted and attractive to its Hindi speaking audience, as the questions and dialogues are all in Hindi. ${ }^{22}$ An analysis of the language used and of some of the questions asked during the show will provide more details on this matter in Sections 2.2 and 2.3.

16 Thomas 2006: 36.

17 It can also be seen as an illustration of the concept of "mediascape" as developed by Appadurai in 1996 (but already coined in 1990). This concept, and those with which it is associated as components of "global cultural flows" (Appadurai 1996: 33) has generated an important critical literature, which this article, however, does not aim to develop here.

18 Moorti 2004: 549.

19 Thomas 2006: 36.

20 Thomas 2006: 36.

21 Roy 2011: 4.

22 Of course, in expressions such as "locally rooted" or "Hindi speaking audience", one must include the widespread and important Indian diaspora, and not only think in terms of a strictly northern Indian audience. 


\subsection{2 $Q$ and $A$}

Taking up the theme of this TV show, the English novel Q\&A was published in 2005 by Doubleday. Vikas Swarup, its author, was then an Indian diplomat who had "served 18 years in the foreign ministry with postings across the world, including Washington, London, Turkey and Ethiopia”. ${ }^{23}$ Swarup started writing his novel while living alone, away from his family, in London in 2003. Fond of thrillers, this genre naturally came to his mind for his first fictional work. Although the novel is written in English, Swarup explicitly links it to the Indian setting, "I don't want to be branded as a writer catering to Western sensitivity. This is an Indian novel, rooted in Indian tradition, written with Indian idioms. It is an Indian story of Indian characters in the Indian milieu". ${ }^{24}$ An analysis of the novel in the following sections will allow us to examine whether his affirmation regarding the "Indianness" of his novel can be confirmed or not. Avoiding the trap of essentialism with regard to "the" Indian identity, a comparison with SDM on the plot of the two stories and on the questions that are asked to the main character (Ram Mohammad Thomas in Q\&A, Jamal Malik in SDM) will provide some clues on this matter. Meanwhile, it is interesting to point out that the novel had been accepted by a publishing house linked to the globalized world: Doubleday is presented as "a division of Transworld Publishers". ${ }^{25}$ The novel won the South Africa's Exclusive Books Boeke Prize in 2006, as well as the Prix Grand Public at the 2007 Paris Book Fair.

Even more telling of the effects of globalization on the novel Q\&A is that it was renamed Slumdog Millionaire after the success of the film in 2008. The reedition reproduced the design of the movie poster in its UK version. An earlier edition (2006) used as its cover the picture of a young boy holding a tea tray and walking in the direction of the reader. The first edition had just the title on the cover and a schematic drawing of a TV set. We might include in this analysis the comments printed on the back cover of the 2009 Black Swan edition, where the Sunday Times describes India as "equally chaotic and enchanting." This might

23 The Rediff Interview 2005: §4. After having worked in Turkey, the US, Ethiopia, the United Kingdom, South Africa and Japan, he was appointed as Official Spokesperson of the Indian Ministry of External Affairs in New Delhi in 2015. In February 2017, he was appointed India's High Commissioner to Canada. He is to date the author of three novels and one collection of short stories.

24 The Rediff Interview 2005: §11.

25 Swarup 2005: 4. 
not be the India Swarup wanted his readers to imagine. ${ }^{26}$ It gives ammunition for Thobani's critique of the "Orientalism” of Slumdog Millionaire, saying that the "film's reception demonstrates the extent to which the power to represent Indians at the global level remains concentrated in 'western' hands" 27 . This remark on the film can be applied to the novel's reception. While the English title of the book changed after the film came out, translated versions (more than 40 to date, already 14 the year of its release) give a hint of what each publishing culture wants to highlight in the novel, in a more or less stereotypical way: Les Fabuleuses Aventures d'un Indien malchanceux qui devint milliardaire in French, Rupien! Rupien! in German, Le dodici domande in Italian, ¿Quiere ser millonario? in Spanish, Kaun banegā arabpati in Hindi, etc.

\subsubsection{Slumdog Millionaire}

Then comes the third piece of this multifaceted global product. The film SDM was quite freely adapted from the book in 2008 by British director Danny Boyle, together with Indian co-director Loveleen Tandan and Simon Beaufoy as scriptwriter, while the celebrated Indian composer A. R. Rahman composed the music - playing an essential role in the success of the film. Being strongly criticised in India - notably by Amitabh Bachchan, ${ }^{28}$ but also by Salman Rushdie and Arundhati Roy ${ }^{29}$ - the film has turned into a blockbuster in the West. It won 8 Oscars, 7 BAFTA, 5 Critics' Choices, and 4 Golden Globes. Somehow, similar to Swarup's assertion quoted above, the intention of Boyle and Beaufoy was to provide an "authentic" picture of India and Mumbai. ${ }^{30}$ With this aim in mind, they both spent much time with the slum-dwellers: "Beaufoy's identity as an authentic screenwriter and Boyle's as a realistic film-maker were thus enabled by their encounters with those living in poverty" ${ }^{31}$ However, in the

26 A more neutral, and accurate, comment was used for the first edition in 2005: "Set in modern India, $Q$ and $A$ presents a kaleidoscopic vision of the struggle of good against evil, and what happens when one boy has no choice in life but to survive."

27 Thobani 2009: 236.

28 Bardhan 2011, Thobani 2009.

29 Mendes 2010.

30 And they succeeded, according to Loveleen Tandan: "For me, it's fully and totally Indian! It's set here, it’s about our world and it feels apna” (Tandan 2009: §8). The claim of "authenticity" - that "elephant in the room" (Lau/Mendes 2012/2013: 139) - behind both authors' intention would open up another question, much debated in Postcolonial studies, that of the rights and authority of representation.

31 Thobani 2009: 236. 
end, the film meets the expectations of the non-Indian viewers: it "is structured to be effortlessly decipherable" by them and transforms "the experience of viewing" it in a "form of armchair tourism". ${ }^{32}$ Of course, the picture is not as unidirectional as this. Through this film, Boyle also pays "homage to popular Hindi cinema of the 1970 s", ${ }^{33}$ and makes use of references to his own previous movies, like in the scene when young Jamal, locked inside an outdoor latrine, dives into the toilet-hole (in order to obtain Amitabh Bachchan's autograph) "in a nod to the famous toilet-bowl interlude in Trainspotting". ${ }^{34}$

A further analysis of their language and especially of their contents will help us clarify the interaction and interpenetration between the local and the global dimensions at play in these three cultural products.

\subsection{Languages of the cultural products}

\subsubsection{KBC}

In the context of globalization, the question of language is of course of prime importance. Choosing a language is never a trivial aspect of the act of creation. We have seen that KBC was meant right from the start to be broadcast in Hindi, in order to reach the biggest possible audience in India. The show came at a time when regional languages were gaining new recognition in the Indian media. It is in this context of national and regional affirmation and competition between TV channels that KBC was launched. ${ }^{35}$

Hosting the show, Amitabh Bachchan always speaks in Hindi, only occasionally using words in English and a few "ready-made" English sentences, especially when talking to the production, like "Can we have that video please?" or the catchword "fully final?", asked when the contestant gives his answer. His Hindi is rather common, with just a few more words stemming from the SanskritHindi register than from the Urdu. If one must be comfortable with Hindi in order to understand the dialogues and Bachchan's touches of humour, viewers who do not know Hindi can nevertheless follow most of the quiz as all questions

32 Mendes 2010: 475.

33 Joshi 2010: 245.

34 Lim 2009: §7. Intertextuality is also present in the novel, notably towards Dickens’s Oliver Twist or Orwell's The Road to Wigan Pier (Korte 2010/2011: 305, 309).

35 It "was launched to coincide and signal the StarPlus channel's repositioning from a globalregional channel offering foreign English-language programming, into a fully subregional Hindi entertainment-oriented channel, taking on the market leaders in Indian prime-time television, namely ZeeTV and SonyET" (Thomas 2006: 36). 
are displayed on the screen in English before appearing in Hindi. ${ }^{36}$ There are, however, some Hindi words (for food, songs, etc.) that are not translated into English, whose meaning might be difficult to grasp for non-Indian viewers. At some point in the episode, a short presentation of the contestant's life and interests is shown, thus localising and individualizing each contestant.

\subsubsection{Q\&A}

In Q\&A, English is the exclusive language. Banerjee (2013), and others, such as Korte (2010/2011), have observed that the kind of English used by the narrator Ram Mohammad Thomas (hereafter Ram) is too sophisticated for a man with such a limited education. Unlike the sort of English one would expect to hear from such a narrator, Swarup's language is in fact "the language of the urban Indian elite generously sprinkled with cliché". 37 The realism of the novel - or rather its realistic intention - is thwarted by the writer's constant playing with idiomatic expressions and his will to please his potential readers.

Using English for his diplomatic activities, but thinking in Hindi, his mother tongue (The Witness), Swarup has thus deliberately chosen to use an international and globalised linguistic medium - Swarup himself acknowledges his "debts" and links to the globalized world when he thanks "Google for helping out" (!) in the Acknowledgements page. ${ }^{38}$ The intention was successful, as the novel has been translated into over 40 different languages, something that would have been impossible - at least so quickly - for a work written in Hindi. The transnational nature of the book and its language is also reflected in the story itself: Ram learns English as a child from Father Timothy, a priest from the north of England, then manages to understand and speak Australian English while serving Colonel Taylor, and has to deal with many different accents and varieties of English while working as a guide at the Taj Mahal. Banerjee writes, "Swarup's oblivion to the question of language and authenticity, the problem of finding a language adequate to the specificity of experience, marks his work as a product for the globalized market”. ${ }^{39}$ While I do agree with the second part of his assertion, I am circumspect in regard to the first. I would

36 From season 1 to 4, questions were only displayed in English, but since season 5, in 2011, questions are also being shown in Hindi, thus reinforcing the initial will to be locally rooted and attract a Hindi speaking audience.

37 Banerjee 2013: 32.

38 Swarup 2005: 303.

39 Banerjee 2013: 32. 
interpret Swarup's choice as deliberate, shaping his language within the contexts of a globalized English - which is more easily translatable than a socially and regionally loaded English.

\subsubsection{SDM}

SDM, on the other hand, tries at first glance to be more realistic and localised than Q\&A in this respect. Boyle and Beaufoy have the young protagonists speak Hindi in the first four episodes. ${ }^{40}$ Yet, this choice can be perceived as locally oriented only by non-Indian viewers. Had the film really been a realistic depiction, children would have spoken Marathi (they grew up in Mumbai's slums), regional Hindi or any other regional language (depending on their family's origin). However, this use of the Hindi language might as well be understood as another form of homage to Bollywood, in the same way Boyle pays homage to Bachchan at the beginning of the movie. Nevertheless, English is present from the outset, as both the inspector and the host of the TV show use it exclusively. After these initial episodes, English becomes the only language of the film; it is then represented both as an international medium of expression - during the Taj Mahal episode when Jamal presents himself as a guide for the foreign tourists and as a global language, in close relation to the world of communication symbolised by the call centre where Jamal is working as a cāy-vālā.

With regard to the question of language, these three cultural products adopt very different strategies. The TV quiz show strongly "glocalizes" the originally English version, because its audience is foremost local and belongs to all social layers of the Indian population. The language used must be of local origin broadly speaking, like Hindi, or more regionally restricted like Malayalam - as the target audience of the show must feel intellectually and sentimentally at ease with the questions and the host's comments. ${ }^{41}$ On the contrary, Vikas Swarup, who belongs to the Indian cosmopolitan elite, records his narrative within his own sociolinguistic sphere, i. e. international English. And this despite his will to locate his novel in Indian reality and the fact that his mother tongue is Hindi. As a result, he makes use of a language meant for a global market, a fact confirmed by the numerous translations of his novel. Finally, SDM

40 Actually, the Hindi dialogues were suggested and written by the co-director Loveleen Tandan, who also casted the film (Desai 2011: 79, Tandan 2009).

41 Within India, the process is repeated in various regional languages, thus somehow carrying on its glocalization effect in regard to the dominant Hindi sphere. On the sensitive issue of language in India, see Montaut 2005. 
plays on both sides. Its first intention is to make the film as locally rooted as possible, by casting mostly Indian actors and making them speak, at least partly, Hindi. However, and despite its authors' claim of authenticity, SDM is above all a western product meant for a western public and acknowledged as a successful story mostly by western critics. It uses the pretext of a local reality to produce a global product, thus corresponding to the process of "grobalization of something". ${ }^{42}$

\subsection{Places of action, participants/characters, and questions and their topics}

\subsubsection{Places of action}

In $\mathrm{KBC}$, the locus of action is of course limited to the standardized television studio. Although there exist minor differences between the national versions of Who Wants to Be a Millionaire? with regard to the design of the television studio, the set can without doubt be seen as a clear instance of a globalized space. ${ }^{43}$ The soundtrack of the show too is another example of a globalized and standardized product. Nevertheless, the multicultural and multiregional dimensions of India are represented by the various origins of the contestants and by the short opening introduction articulating the players' background.

In Q\&A, the action takes place alternatively in Mumbai and Delhi, with the exception of the longest and most important episode occurring in Agra. Characters live in slums and orphanages, but also in the annex of a church, and in residences of diplomats and movie stars. Thus, several cultural and economic aspects of India are covered by these locations. Without being very concrete in his descriptions - it is certainly not a regionalist novel, nor an ethnographic tale - Swarup's story nevertheless draws a plausible portrait of the country.

This contrasts with the relatively Mumbai-centred plot of SDM - with the exception of the episode in Agra, which is, however, less developed than in Q\&A. Besides highlighting Mumbai's slums - which have given rise to "slum tourism"44 - the film also stresses the changing aspect of a city becoming the

42 Ritzer 2003.

43 What makes it different from a "non-place” in Augé's terminology (Augé 1992) is the fact that, despite its uniform and unmarked design, this space nevertheless creates important social links, no matter how ephemeral they can be.

44 Mendes 2010, using Salman Rushdie’s expression. 
"centre of the world" (according to Salim's words), partly because of its growing economic power and as a major place for call centres. Despite its realistic intentions, Boyle represents an India that is the result of an Orientalist discourse. Neither this representation nor the image of Mumbai as being the new centre of a globalized world convey a concrete and localized India.

The "transitional place" of the train, present both in Q\&A and SDM, also gives some information on the way their respective authors wanted India to be represented. In SDM, the scene introduces the transition from Jamal and Salim's childhood to their adolescence, and linguistically from Hindi to English. The scene, which benefits a lot from Rahman's music, looks like a "touristic video clip" encouraging the viewer to visit this "Incredible India", and ends - of course - in front of the Taj Mahal. Respecting the usual, global-oriented perception of India, the two boys are shown as the viewer expects them to be, i. e. as two poor Indian children, traveling on the roof of trains, while living from petty jobs and stealing food. In this way, they remain confined to their social background and no class border is thus crossed or transgressed. The topic of the train is all the more central to the film, as the final scene, where Jamal meets Latika again for a feel-good ending, is set in Victoria Station in Mumbai.

Swarup, on the contrary, allows his protagonist to cross this border: "Train journeys are about possibilities. They denote a change in state". ${ }^{45}$ This happens when Ram leaves Delhi to Mumbai, after having earned fifty thousand rupees from working for Colonel Taylor, the diplomat.

If you were to search for me in this crowded maze [i. e. New Delhi Railway Station], where would you look? You would probably try to find me among the dozens of street children stretched out on the smooth concrete floor in various stages or rest and slumber. You might even imagine me as an adolescent hawker, peddling plastic bottles containing tap water from the station's toilet as pure Himalayan aqua minerale. ${ }^{46}[\ldots]$

Well, think again, because I am neither hawker, nor porter, nor sweeper. Today I am a bona fide passenger, travelling to Mumbai, in the sleeper class, no less, and with a proper reservation. I am wearing a starched white bush shirt made of one hundred per cent cotton and Levi jeans - yes, Levi jeans, bought from the Tibetan Market. ${ }^{47}$

Here, the narrator deliberately plays with what the reader would normally expect of the situation of an orphan like Ram. However, after going first against the grain of these expectations, he deems it necessary to get back to the "reality" of the social system and, a few pages later, has the boy lose all his money in a

45 Swarup 2005: 150.

46 In fact, this is exactly what Jamal and Salim are doing later on in SDM.

47 Swarup 2005: 146-147. 
robbery and commit a murder with a gun. Ram is thus narratively forced, as it were, to respect the expected social order in India. An interesting point in relation to our topic is the way Ram's temporary change of status is described. Sharing the world of people travelling in a sleeper-class coach means wearing Levi jeans and a wristwatch (albeit a fake one). Ram now belongs to middleclass society: "Like them, I too can now watch middle-class soaps, play Nintendo and visit Kids Mart at weekends". ${ }^{48}$ Clearly, this society, and the higher position it implies, is linked to the global - here one should use "grobal" - world, where consumption and entertainment are dominant.

\subsubsection{Participants/characters}

It would take too long to analyse all the participants and characters present in the episodes of KBC and in the two fictions. ${ }^{49}$ For our purpose, I will only focus on two characters; firstly, the main protagonist of the novel and the film, and secondly, Amitabh Bachchan. For his main protagonist, Ram Mohammad Thomas, Swarup chose an unlikely name for sure, whose origin is explained in detail in the book. ${ }^{50}$ With this name, he certainly wanted to give to his story a clear "secularist" tone, in the manner Gandhi would have used the term to elevate all religions to the same level in the society. ${ }^{51}$ This openly contrasts with Boyle and Beaufoy's choice to give him an exclusive Muslim name and origin (Jamal Malik), but also with the explicit reference to the communalist violence leaving its mark on the film at the beginning of it. Although Swarup's choice might be viewed as utopian in contemporary India, at least it shows a positive and complex image of religion. If the name of Ram Mohammad Thomas might look bizarre, it nevertheless illustrates an aspect of the secularist view of religion that pertains too to India. Perceiving this hybrid name in a negative way, Thobani considers, on the contrary, that Swarup has "deliberately obscured the religious identity" of the protagonist. ${ }^{52}$ It appears that Swarup anticipated this kind of comment, when he has Inspector Godbole say: "what kind of a nonsense name is that, mixing up all the religions? Couldn't your

48 Swarup 2005: 150.

49 For a brief comparison of Q\&A's and SDM's characters, see Bulger 2009: 166-169.

50 Swarup 2005: 42-45.

51 Banerjee sees in this choice a clear reference to "the title of the popular 1977 film Amar Akbar Anthony" (2013: 38). On Indian secularism, see Embree 1990; for a further analysis of the concept and its critics, see Bhargava 2008.

52 Thobani 2009: 228. 
mother decide who your father was?"53 For their part, Boyle and Beaufoy were decisive: they opted for a Muslim name, avoiding any religious ambiguity and emphasising their western perception of India through the representation of Hindu communalism and Muslim terror. ${ }^{54}$

One of the key figures of these three narratives, if not the key figure, is Amitabh Bachchan. Firstly, he hosts the TV show and gives it a very personal and human touch, contrary to Prem Kumar, the fictional host of Q\&A and SDM (played by Anil Kapoor). Nevertheless, the 1970s movie star ghost haunts the mind of the audience and the viewers. As Visvanathan writes it, "Amitabh's style is to underplay himself but the legend is all there". ${ }^{55}$ Amitabh Bachchan gives to the TV game show a unique Indian touch by interjecting long comments in relation to current Indian events. For instance, when, on the last day of 2013 Navratri, he asks nine questions to the audience on how women are actually being treated in society, or when, one month before, he comments on the heroism of the soldiers during the "Himalayan Tsunami" of that same year. His hosting illustrates the way glocalization works: the ability and skill to adopt a global show and transform it into something meaningful for the local audience. For all these reasons (the contestants' affective and devoted relations with Bachchan, and his running commentary on current events), the Hindi version of Who Wants to Be a Millionaire? demonstrates the adaptive creativity of the process of glocalization. This somewhat diminishes the force of the following affirmation of Desai, who writes that in the nationally adapted versions, "the nature of knowledge and knowing itself remains Eurocentric as the quiz show is merely adapted for locations elsewhere". ${ }^{56}$

Amitabh Bachchan is also present in the novel Q\&A, even if only briefly mentioned as the highest standard of the game: compared to Bachchan, points out the Commissioner, Prem Kumar, the "B-grade actor" and host of the fictive Who Will Win A Billion?, is "not half as famous". ${ }^{57}$ If the reverence for Amitabh Bachchan is less explicit in the novel than in the film, it does not mean that the actor was less important to Swarup than to Boyle. In an interview, Swarup recognises having been "definitely impressed" by the actor's performance in the TV show. Moreover, his respect is also personally linked to his family's history: his grandfather "was a friend of" Amitabh's father, the famous Hindi

53 Swarup 2005: 11.

54 On this perception, see Desai 2011 and Thobani 2009.

55 Visvanathan 2000: 3091.

56 Desai 2011: 83-84 (emphasis is mine).

57 Swarup 2005: 13. 
poet, Harivansh Rai 'Bachchan'. ${ }^{58}$ In this case, contrary to SDM, no mention is explicitly made of the "angry young man" Bachchan was playing in the 1970s. ${ }^{59}$

In SDM, it is the actor's career that becomes the focus of the first episode of the film, thus turning SDM into "an homage to popular Hindi cinema of the 1970s in the period when that cinema was beginning to be named Bollywood". 60 By putting Bachchan at the forefront, Boyle's blockbuster translates him (and a certain image of India and Bollywood) from the local to the global. Linked to this first question, the dialogue that takes place in the police station is interesting in this respect. One sees Jamal correctly answering the question in the quiz show and then adding in the police station:

Jamal. You don't have to be a genius.

Policeman. I knew it was Amitabh Bachchan!

Jamal. Like I said, you don't have to be a genius ... He's the most famous man in India! ${ }^{61}$

On the one hand, the script ironizes the alleged stupidity of the policemen: even ignorant people like them must know this. On the other hand, Boyle and Beaufoy feel it necessary to clarify, for the ignorant western spectator, how famous Amitabh Bachchan is! The ignorant one is no more Jamal the $c \bar{a} y-v \bar{a} l \bar{a}$, but the alleged educated non-Indian viewer. A similar process happens in Q\&A, as when Ram and Salim are taught Surdas's bhajans. The narrator feels it necessary to write at this point: "Who is Surdas?/He is the most famous of all bhakti singers, who composed thousands of songs in praise of Lord Krishna" ${ }^{62}$ If both globalization and knowledge surely imply power, being an agent of globalization does not, however, necessarily mean possessing knowledge. How does this relation between knowledge and globalization emerge from the questions of the quizzes?

\subsubsection{Questions and their topics}

When analysing the quizzes of KBC, Q\&A, and SDM with this question in mind, one can focus on two related aspects: first, the degree of difficulty of the questions in the sequence, and second, the degree to which the knowledge they imply is mostly locally or globally oriented. For this analysis, the series

58 The Rediff Interview 2005: §37.

59 On this topos, see Joshi 2010, Roy 2011, Thobani 2009, Visvanathan 2000.

60 Joshi 2010: 245, who adds on the same page: "Thus, the first question Jamal is asked on the quiz show is the name of the actor who starred in the 1973 blockbuster, Zanjeer".

61 Boyle 2008.

62 Swarup 2005: 97. 
of questions asked to the second contestant in the 12th October 2013 broadcast (season 7) is used in comparison with the questions in Q\&A and SDM (see table in the Annexe).

In relation to the first of these aspects, Swarup explains in an interview that he wanted his novel to follow the pattern of the original quiz show, "I had to follow the etiquette of the quiz show. In the quiz show, easy questions are at the beginning and the tough one (sic) are at the end. It has to be good mix of questions on sports, science, history and other subjects". ${ }^{63}$ Supposing that Swarup faithfully followed this pattern, and knowing that he had the Indian setting in mind (according to his own words, see 2.1.2 supra), the nature of the questions in Q\&A should give us a clue with regard to what the author assumes to be easy and what difficult for a young uneducated Indian - even if Ram knows English surprisingly well, as well as some other very unexpected facts. One may assume that for such a young man, the more street-contextualised the question is, the easier the answer must be - this is actually the essence of Jamal's justification to the Inspector's question in SDM after he admits being unaware of the answer to the question on the national emblem.

However, the series of questions in the novel (see the Annexe, second column of the table) strongly contradicts its author's assertion: while the sequence of questions in KBC (first column of the table) does follow an increasing level of difficulty for an Indian contestant (questions not meant for the international audience, as they are mainly India-oriented), in Q\&A the difficulty is not at all progressive for a contestant like Ram, mainly because the questions require a vast, mostly western-oriented, knowledge. Therefore, the progression Swarup had in mind must rather be linked to the way he imagined his readers' general knowledge... unless he eventually abandoned his initial idea. When looking at the nature of the questions in Q\&A, one sees an alternation between Indian and western-contextualized questions, with a slight predominance of the latter. The sequence of questions is certainly meant for an Indian audience. Nevertheless, the substance and form of the questions carry the idea that global knowledge from the West have a higher value, both because western-contextualized questions come at the end of the quiz and are therefore equal to the highest amounts of rupees, and because the contestants are more likely not to know the correct answer. Ram is unable to answers the last questions, on Beethoven's music and Shakespeare's plays, but he nevertheless wins the game with the help of an Indian professor of English literature and through the threat he makes on the host, in retaliation for crimes the latter committed earlier in the story. Thus, despite the intention to set the quiz in an Indian

63 The Rediff Interview 2005: §28. 
context, the overall tendency of the series of questions gives the highest value and predominance to the western world and western knowledge.

What about the local/global aspect of the quiz in KBC? In the sequence of questions selected for this case study, the majority of the questions are clearly India-oriented, thus necessitating from the contestant a good local - or rather, national - knowledge: there are some questions, like the audio clip of Narendra Modi's voice, which cannot be answered unless one lives in India or has an active knowledge of Indian politics. Besides two general questions, which do not require practical knowledge (a question on the courses at Presidency University in Kolkata, and a question related to the history of science), only two questions belong to the global world: one is linked to Christianity (question 7) and the other is on Facebook (question 2), the perfect product of grobalization. According to this series of questions (and to others in $\mathrm{KBC}$ ), western culture and globalization do not look so important in comparison to the questions related to the Indian context. Except for a few questions, the content of the quiz clearly represents an adaptation to a local if not a national context. ${ }^{64}$ It can be added, in relation to Jamal's remark above, that someone from his background would certainly have difficulties answering most of these questions, which correspond to a middle-high level of education and cultural knowledge. With this kind of questions, the effect on Ram or Jamal will certainly be the same as a series of western-contextualized questions on a middle-classed Indian contestant: a feeling of ignorance and otherness.

Questions in SDM present a mix of KBC and Q\&A. The first four questions are, without doubt, based on the Indian context and can quite easily be answered by any Indian contestant. Nevertheless, they are not especially related to practical and local experiences of Indian life. On the contrary, they can be described as the general knowledge one can expect from western viewers interested in India and its culture. The second part of the sequence, however, differs radically from KBC and Q\&A, as not a single question appears to be related to the Indian context: they are all linked to western culture. Overall, questions in SDM are comparatively much easier than those in Q\&A and KBC - at least if we adopt the point of view of a western educated contestant. Indeed, they are much more related to the western, English-speaking world, and look more similar to the kind of questions one can find in British and US versions of the quiz show.

64 This - a nationally oriented adaptation - is also the picture that emerges from a look at questions in other national versions. In the context of KBC, it must, however, be added that the nation is primarily seen as Hindu, especially in the more recent series, according to the topic of the religion-oriented questions. No question is asked on religious topics demanding a specifically Islamic knowledge. 
Thus, the quiz in SDM accentuates the feeling, firstly, that this film was made essentially for a western audience and, secondly, that it strongly follows the idea that western knowledge is, or must be, eminently global. In the catchy formulation of Desai, it can be said that these specific questions, together with "the medium of television" and "the reality quiz show" establish "Jamal as a neoliberal global citizen who can be recognised via re-Orientalism by the West". ${ }^{65}$ If the location of the film is clearly set in the Indian context, the questions in the quiz invoke little information on India itself and are rather meant for a predominantly English-speaking audience.

Finally, we can sum up the topic of this section by comparing the role these quizzes play in each of the three narratives. In $\mathrm{KBC}$, the quiz is central and identical to the narrative; it constitutes it and makes the contestant and the audience identify with the nation, especially with dominant northern Hindi culture. In Q\&A, even if it obviously takes less space than in $\mathrm{KBC}$, it is nevertheless essential to the narrative and gives clues to many of its aspects. In this case, a dimension of social justice and love is added to the narration. Finally, in SDM, the quiz is nothing more than a pretext for narrating the India Boyle and Beaufoy wanted to present to the western world.

\section{Concluding remarks}

These cultural products belong to the globalized world in terms of their frame of production and their authors/agents. However, the intention of their authors/agents is in every case to make the product look local, Indian, "authentic". The language used and the content of the questions nevertheless contradict their intention to varying degrees. In other words, a similarly global, multinational setting of production does not imply similar outcomes with regard to the representation and the direction of the dynamic relationship between globality and locality.

KBC has succeeded in adapting a grobal product par excellence into a muchacclaimed Indian TV show (thousands of people register for the show and wait to be part of the selection). It can be described as a successful, if not perfect, instance of glocalization if one look at the way it plays with globalization and local identity: "By renegotiating the boundaries of the global and the regional, these programmes are able to hail the viewer simultaneously as a cosmopolitan and a vernacular subject". ${ }^{66}$

65 Desai 2011: 82.

66 Moorti 2004: 550. 
If Q\&A and SDM have shared a similar successful destiny, they have nevertheless, in comparison with $\mathrm{KBC}$, followed a different trajectory and reached a very different audience. Basing their narratives on supposedly local features, they ultimately set them in a dominantly western framework of representation and reception. This is especially evident for SDM - a little less for Q\&A, which appears to be more hybrid in this regard. Behind the explicit will of Swarup to set his story in an Indian context and to address an Indian audience, the final product is actually a narrative that addresses first of all western readers, or more generally an international readership.

In the final reckoning, both SDM and Q\&A are global-oriented, but while Q\&A remains closer to the KBC pattern and to local criteria, alternating between the Indian context and the international world to which Swarup belongs, SDM follows a model of production that can be seen as an example of grobalization. The India it represents, based on clichés, is deliberately meant to please the expectations of the widest possible public, and any excessively specific feature, narrative complexity (like in Swarup's novel), or strongly context-based information is replaced by content and form belonging to a global, shared and easily understandable world: poverty, prostitution and call centres are everywhere and belong to nowhere.

Thus, by analysing these three related but distinct cultural products, one can see that based on a similar social phenomenon (quiz and entertainment set in an Indian context through the lenses of globalization), cultural products nevertheless provide various responses to the process of globalization. Similar intentions and settings are not necessarily implying similar results: while a highly globalized cultural product like Who Wants to Be a Millionaire? is transformed in a glocal, if not local, product strongly linked to the Indian context, a fictional work like SDM, claiming Indian authenticity as its intention, ends up erasing almost all cultural marks, producing a highly westernized, if not globalized, narrative. In order to highlight differences between various cultural products stemming and responding to the process of globalization, it is necessary to look at each of their constitutive aspects (production, intention, content, language, etc.). But it is equally important to point out the (hidden) distinction between the author's expressed intention and the actual result in terms of effect on the audience and place occupied by the product within the globalized world.

Another conclusion emerges from this analysis. When looking at the contents of these three cultural products and the way they are potentially exportable and globalized, it appears that Indian-based references remain, in the twentyfirst century, primarily attached to the ideas of "locality" and "authenticity" (cf. the claims by Swarup and Boyle). On the contrary, western-based references are still viewed as a part of universal knowledge, and thus similar - to some extent 
at least - to globality. Successful glocalization is still a process that moves from the "global" West (especially from the Anglo-American world) to "local" cultures such as the Indian, and not vice-versa - at least in the field of narratives. ${ }^{67}$

\title{
Annexe: List of questions in KBC, Q\&A, and SDM (right answer given after the $\rightarrow$ )
}

\author{
KBC (12th Oct. 2013, 2nd Q\&A \\ SDM \\ contestant)
}

1. Which of these ingredients In which film did Armaan Ali Who was the star in the must be present in 'lassi', $\quad$ star with Priya Kapoor for 1973 hit film 'Zanjeer'? $\rightarrow$ 'mattha' and 'chaach'? $\rightarrow \quad$ the very first time? $\rightarrow \quad$ Amitabh Bachchan dahi Betrayal

2. On Facebook, which of these What is the sequence of What is written underneath buttons is denoted by a letters normally inscribed on 'thumbs up' symbol? $\rightarrow$ like a cross? $\rightarrow$ INRI $(R M T$ was emblem? $\rightarrow[$ Truth alone allowed to choose the triumphs] question)

3. Ram Charan Teja, who made Which is the smallest planet What is God Rama his film debut with 'Zanjeer', in our solar system? $\rightarrow$ Pluto famously holding in his is the son of which actor? $\rightarrow$ Chiranjeevi

4. Identify the speaker from this audio clip. $\rightarrow N$. Modi

Surdas, the blind poet, was a devotee of which god? $\rightarrow$ Krishna right hand? $\rightarrow A$ bow \& arrow

The song 'Darshan Do Ghanshyam' was written by which famous Indian Poet? $\rightarrow$ Surdas

5. Presidency Univ., Kolkata,

When a government On a 100 USD bill, there is will introduce a new course declares a foreign diplomat from 2014 on which of these persona non grata, what the portrait of which subjects? $\rightarrow$ [uses the does it mean? $\rightarrow$ diplomat is Benjamin Franklin lifeline "phone a friend", not acceptable

\section{American statesman $\rightarrow$} and then the lifeline "flip the question"]

67 The antithetical example of yoga, for instance, belongs to another category of cultural products. On this topic, see Burger 2006. 


\begin{tabular}{lll}
\hline $\begin{array}{l}\text { KBC (12th Oct. 2013, 2nd } \\
\text { contestant) }\end{array}$ & Q\&A \\
\hline
\end{tabular}

6. Which river, a headstream of Ganga, flows by the

What is the capital of Papua

... not shown ...

Badrinath shrine? $\rightarrow$

New Guinea? $\rightarrow$ Port

Alakananda

7. How do we better know Who invented the revolver?

Jorge Mario Bergoglio, who $\rightarrow$ Samuel Colt

came to prominence in March 2013? $\rightarrow$ Pope Francis

8. Who gave the title "Flying Which is the highest award Sikh' to the great athlete for gallantry given to the Milkha Singh? $\rightarrow$ Gen Ayub Indian armed forces? $\rightarrow$ Khan Param Vir Chakra

9. According to the Rigveda, to How many Test centuries which god does the sun has India's greatest

Who invented the revolver? hand over his effulgence in the evening and take it back batsman Sachin Malvankar in the morning? $\rightarrow$ Agni

10. Who was the first child in the world to be born via the IVF method? $\rightarrow$ Louise Brown scored? $\rightarrow 36$

Neelima Kumari, the Tragedy Queen, won the National

Cambridge Circus is in Award in which year? $\rightarrow$ $1985^{\mathrm{b}}$

11. In which of these states In which play by $\rightarrow$ Samuel Colt have both father and daughter served as chief Shakespeare do we find the character Costard? $\rightarrow$ Love's minister? $\rightarrow$ [Goa] QuITS Labour's Lost (lifeline: help from the Eng. teacher) $12 a$. What was the name of Mumtaz Mahal's father? $\rightarrow$ Asaf Jah which UK city? $\rightarrow$ London

Which cricketer has scored the most 1 st class centuries in history? $\rightarrow$ Jack Hobbs

In 'The Three Musketeers', what was the name of the third Musketeer? $\rightarrow$ Aramis WINS

$12 b$.

$$
\begin{aligned}
& \rightarrow \text { CHANGE: Beethoven's } \\
& \text { Piano Sonata } N^{\circ} 29, \text { Opus } \\
& 106, \text { is in which key? } \rightarrow \\
& \text { threat by Ram } \rightarrow \text { answer } \rightarrow \\
& \text { coin } \rightarrow \text { B flat major WiNS }
\end{aligned}
$$

\footnotetext{
aNew question: "A species of which of these birds is the fastest while swimming underwater?" $\rightarrow$ penguin.

${ }^{\mathrm{b}}$ During the preceding break, however, Prem Kumar made him believe that the question would be on the length of the Palk Strait between India and Sri Lanka, and gave him the answer.
} 


\section{Bibliography}

Appadurai, Arjun (1996): Modernity at Large: Cultural Dimensions of Globalization. Minneapolis/London: University of Minnesota Press.

Augé, Marc (1992): Non-Lieux: Introduction à une anthropologie de la surmodernité. [Paris]: Éditions du Seuil.

Banaji, Shakuntala (2010): “Seduced 'Outsiders' versus Sceptical 'Insiders’?: Slumdog Millionaire through Its Re/Viewers”. Participations: Journal of Audience and Reception Studies 7: 1-24.

Banerjee, Chinmoy (2013): "Vikas Swarup: Writing India in Global Time”. In: Postliberalization Indian Novels in English: Politics of Global Reception and Awards. Edited by Aysha Iqbal Viswamohan. London/New York/Delhi: Anthem Press, 31-39.

Bardhan, Nilanjana (2011): “Slumdog Millionaire Meets 'India Shining’: (Trans)national Narrations of Identity in South Asian Diaspora”. Journal of International and Intercultural Communication 4.1: 42-61.

Bhargava, Rajeev (ed.) (2008 [1998]): Secularism and Its Critics. New Delhi: Oxford University Press.

Bhattacharya, Nandini (2013): Hindi Cinema: Repeating the Subject. London/New York: Routledge.

Bhattacharya, Spandan (2009): "Jamal Lacks It: Game Show Politics and Rise of Individual in Slumdog Millionaire". Silhouette 7: 87-95.

Bhattacharya Mehta, Rini / Pandharipande, Rajeshwari V. (eds.) (2011): Bollywood and Globalization: Indian Popular Cinema, Nation, and Diaspora. London/New York/Delhi: Anthem Press.

Boyle, Danny (2008): Slumdog millionaire. London: Celador Films/Film4.

Bulger, Laura Fernanda (2009): "From Q\&A to Slumdog Millionaire - It's Written”. Comunicação \& Cultura 8: 161-172.

Burger, Maya (2006): “Une posture inversée: le yoga global”. In: Comparer les comparatismes, Perspectives sur l'histoire et les sciences des religions. Edited by Maya Burger and Claude Calame. Paris: Edidit/Milan: Archè, 161-188.

Desai, Jigna (2011): "Pulp Frictions". In: Re-Orientalism and South Asian Identity Politics: The Oriental Other within. Edited by Lisa Lau and Ana Cristina Mendes. London/New York: Routledge, 74-90.

Dudrah, Rajinder (2012): Bollywood Travels: Culture, Diaspora and Border Crossings in Popular Hindi Cinema. London/New York: Routledge.

Embree, Ainslie T. (1990): Utopias in Conflict: Religion and Nationalism in Modern India. Berkeley/Los Angeles/Oxford: University of California Press.

Gehlawat, Ajay (ed.) (2013): The Slumdog Phenomenon: A Critical Anthology. London/New York/ Delhi: Anthem Press.

Gehlawat, Ajay (2015): Twenty-first Century Bollywood. London/New York: Routledge.

Ghosh, Tanushree (2015): “Yet We Believe his Triumph Might Surely Be ours': The Dickensian Liberalism of Slumdog Millionaire”. Neo-Victorian Studies 8.1: 77-106.

Giddens, Anthony (1990): The Consequences of Modernity. Stanford: Stanford UP. Hall, Stuart (1991): “The Local and the Global: Globalization and Ethnicity." In: Culture, Globalization and the World-system: Contemporary Conditions for the Representation of 
Identity. Edited by Anthony D. King. Houndmills/Basingstoke: Macmillan; Binghamton: Department of Art and Art History-State University of New York, 19-39.

Joshi, Priya (2010): "Bollylite in America”. South Asian Popular Culture 8.3: 245-259.

Kaur, Raminder / Sinha, Ajay J. (eds.) (2005): Bollyworld: Popular Indian Cinema through a Transnational Lens. New Delhi/Thousand Oaks/London: Sage.

Korte, Barbara (2010/2011): “Can the Indigent Speak? Poverty Studies, the Postcolonial and Global Appeal of $Q$ \& A and The White Tiger”. Connotations 20.2-3: 293-312.

Lamsal, Tika (2010): “Global Audiences, Local Images: The Question of Exoticization in Slumdog Millionaire". Bodhi: An Interdisciplinary Journal 4.1: 198-209.

Lau, Lisa / Mendes, Ana Cristina (2012/2013): “Authorities of Representation: Speaking To and Speaking For: A Response to Barbara Korte”. Connotations 22.1: 137-143.

Lechner, Frank (2005): "Globalization”. In: Encyclopedia of Social Theory. Edited by George Ritzer. Thousand Oaks/London/New Delhi: Sage, 330-333.

Lim, Dennis (2009): “What, Exactly, Is Slumdog Millionaire?” Slate, 26 January 2009. http:// www.slate.com/articles/arts/the_oscars/2009/01/what_exactly_is_slumdog_millionaire. html (10/10/2019).

Livingston, Robert Eric (2001): “Glocal Knowledges: Agency and Place in Literary Studies”. PMLA 116.1: 145-157.

Mendes, Ana Cristina (2010): "Showcasing India Unshining: Film Tourism in Danny Boyle's Slumdog Millionaire". Third Text 24.4: 471-479.

Montaut, Annie (2005): “Colonial Language Classification, Post-Colonial Language Movements, and the Grassroots Multilingualism Ethos in India". In: Living Together Separately: Cultural India in History and Politics. Edited by Mushirul Hasan and Asim Roy. New Delhi: Oxford University Press, 75-116.

Moorti, Sujata (2004): "Fashioning a Cosmopolitan Tamil Identity: Game Shows, Commodities and Cultural Identity”. Media Culture Society 26: 549-567.

Mudambi, Anjana (2013): "Another Look At Orientalism: (An)Othering in Slumdog Millionaire". Howard Journal of Communications 24.3: 275-292.

Nye, Joseph S. (2004): Soft Power: The Means to Success in World Politics. New York: Public Affairs.

Raj, Sony Jalarajan / Sreekumar, Roginee (2011): “Slums, Oscars and Markets: 'Indianness' in Slumdog Millionaire". Mass Communicator 5.3: 4-13.

Ranjan, Pranav / Sehdev, Razia / Bhatnagar, Yuvraj (2013): “Impact of Celebrity Personality on Audience Preferences: A Case of 'Kaun Banega Crorepati”'. IIMS Journal of Management Science 4.2: 168-177.

Ritzer, George (2003): “Rethinking Globalization: Glocalization/Grobalization and Something/ Nothing”. Sociological Theory 21.3: 193-209.

Ritzer, George (2004): The Globalization of Nothing. Thousand Oaks, CA: Pine Forge Press.

Robertson, Roland (1992): Globalization: Social Theory and Global Culture. London/Newbury Park/New Delhi: Sage.

Robertson, Roland (1994): “Globalisation or Glocalisation?”. Journal of International Communication 1.1: 33-52.

Roy, Anjali Gera / Huat, Chua Beng (eds.) (2012): Travels of Bollywood Cinema: From Bombay to LA. New Delhi: Oxford University Press.

Roy, Enakshi (2011): "The Indian Game Show Kaun Banega Crorepati in the context of Media Globalization and Glocalization”. Electronic Thesis or Dissertation. Ohio University. 
OhioLINK Electronic Theses and Dissertations Center. https://etd.ohiolink.edu/ (09/10/ 2019).

Schaefer, David J. / Karan, Kavita (eds.) (2013): Bollywood and Globalization: The Global Power of Popular Hindi Cinema. London/New York: Routledge.

Snell, Heather (2016): "Uses and Abuses of the Child Figure in Slumdog Millionaire and Vikus Swarup's Q \& A". Adaptation 9.2: 234-248.

Stephens Duncan, Rebecca (2011): "Reading Slumdog Millionaire across Cultures". The Journal of Commonwealth Literature 46.2: 311-326.

Swarup, Vikas (2005): $Q$ and $A$. London [etc.]: Doubleday.

Tandan, Loveleen (2009): "I sometimes feel like l'm the off-screen 'millionaire': Loveleen." Hindustan Times, 01 January 2009. https://www.hindustantimes.com/india/i-sometimesfeel-like-i-m-the-off-screen-millionaire-loveleen/story-CQHVxHCWC8N4bIC2vw0eQL.html $(11 / 15 / 2019)$.

The Rediff Interview. (2005): “Vikas Swarup: Who Wants to Be a Millionaire?" 1 February 2005. http://www.rediff.com/news/2005/feb/02inter1.htm (10/10/2019).

Thobani, Sunera (2009): "Slumdogs and Superstars: Negotiating the Culture of Terror". Studies in South Asian Film and Media 1.2: 227-248.

Thomas, Amos Owen (2006): "Cultural Economics of TV Programme Cloning: Or Why India Has Produced Multi-“Millionaires”. International Journal of Emerging Markets 1.1: 35-47.

Thussu, Daya Kishan (2008): “The Globalization of 'Bollywood': The Hype and the Hope”. In: Global Bollywood. Edited by Anandam P. Kavoori and Aswin Punathambekar. New York: New York University Press, 97-113.

Tyree, J. M. (2009): "Slumdog Millionaire and The Curious Case of Benjamin Button". Film Quarterly 62.4: 34-38.

Vanfasse, Nathalie (2012): "Charles Dickens in Twenty-First-Century India: A Study of the Novel Q \& A by Vikas Swarup and its Film Adaptation by Danny Boyle”. Études anglaises 65.1: 718.

Visvanathan, Shiv (2000): “The Crorepati Narratives". Economic and Political Weekly 35.35/36: 3089-3092.

Wilson, Rob / Dissanayake, Vimal (eds.) (1996): Global/Local: Cultural Production and the Transnational Imaginary. Durham/London: Duke UP. 